\title{
Pengaruh Insentif Terhadap Kinerja Karyawan Guna Memotivasi dan Meningkatkan Profitabilitas (Studi Kasus Pada PT. Bentara Sinergies Multi Finance) Rohaelis Nuraisyiah $^{1}$,Anggi Haerani ${ }^{2}$ rohaelisnuraisiah@unbaja.ac.id ${ }^{1}$ anggihaerani@unbaja.ac.id ${ }^{2}$
}

\begin{abstract}
Penelitian ini bertujuan untuk menguji secara empiris dari beberapa variable yang mempengaruhi Kinerja Karyawan. Ada dua variabel yaitu motivasi dan insentif. Penelitian ini menggunakan Studi Kasus Pada PT. Bentara Sinergies Multi Finance yang diambil dengan metode aksidental sampling. Alat analisis yang digunakan adalah regresi linear berganda. Hasil penelitian ini menunjukan secara serempak semua variabel yaitu Motivasi dan Insentif berpengaruh terhadap Kinerja Karyawan. Variabel Motivasi saja yang mempengaruhi Kinerja Karyawan secara parsial, sedangkan faktor Insentif berpengaruh tidak signifikan terhadap Kinerja Karyawan.
\end{abstract}

Kata kunci: Motivasi, Insentif dan Kinerja Karyawan.

\section{ABSTRACT}

The research aims to empirically from several variables that effect Employee Performance. There are two variables that is Motivation and Incentives. This study uses a case study on the PT. Bentara Sinergies multifinance Facotry, were taken by aksidental sampling method. Analysis tool used is multiple linear regression. The results showed that all variables simultaneously Motivation and Incentives of effect Employee Performance. Variables that influence the Motivation of partial Employee Performance, while the Incentives does not significantly effect on Employee Performance.

Keyword: Motivation, Incentives and Employee Performance. 
JUMANIS - BAJA VOL 4 NO 1 Prodi Kewirausahaan Februari 2022

ISSN : 2686-0554

ESSN : 2686-5939

DOI : 10.47080

\section{PENDAHULUAN}

Pada saat ini perkembangan usaha bisnis sangat ketat, untuk menghadapi persaingan di era globalisasi perusahaan dituntut untuk bekerja secara efisien dan efektif. Persaingan yang semakin ketat menyebabkan perusahaan untuk dapat meningkatkan daya saing dalam rangka menjaga kelangsungan hidup dan tujuan perusahaan. Untuk memperoleh kontribusi yang maksimal, perusahaan harus dapat memperlakukan sumber daya manusia sebagaimana layaknya faktor produksi lainnya yang dimiliki perusahaan. Oleh karena itu wajib dilindungi dan dipelihara sehingga mampu memberikan kontribusi bagi perusahaan.

Motivasi menjadi hal yang sangat penting bagi setiap perusahaan, terutama manfaat bagi karyawan dan perusahaan. Motivasi akan mendorong karyawan untuk lebih berprestasi dan produktif. Begitu pula motivasi dalam perusahaan dalam rangka peningkatan produksi dan penekanan biaya melalui perbaikan sikap dan tingkah laku karyawan. Dengan adanya motivasi maka dapat dilihat pengaruhnya terhadap kinerja karyawan, dimana karyawan akan melakukan tindakan atas dasar keinginan untuk berprestasi dan memperoleh jabatan lebih tinggi di perusahaan.

Sumber daya manusia merupakan harta yang paling penting bagi suatu organisasi, oleh karena itu maka diperlukan perhatian lebih serius terhadap tugas yang dikerjakan sehingga tujuan perusahaan tercapai. Dengan motivasi yang tinggi, karyawan akan bekerja lebih giat didalam melaksanakan pekerjaannya. Sebaliknya dengan motivasi yang rendah karyawan tidak mempunyai semangat kerja, mudah menyerah dan kesulitan dalam melaksakan pekerjaannya.

Selain faktor motivasi, untuk mencapai tujuan dan peningkatan produktivitas perusahaan diperlukan adanya dukungan yang kuat dari keuangan dan tunjangan-tunjangan lain dalam perusahaan. Perusahaan perlu memberikan suatu penghargaan bagi karyawan yang berprestasi baik dan hal ini akan membuat karyawan bekerja sebaik mungkin agar menerima penghargaan dan imbalan yang lebih besar disamping tunjangan-tunjangan lain yang telah disediakan oleh perusahaan. Bentuk pembayaran dan penghargaan atas kerja karyawan yang tepat akan menghasilkan pencapaian produktivitas yang lebih tinggi, hal itu mencakup sistem pemberian insentif yang tepat serta usaha-usaha lain untuk menambah semangat dan kepuasan kerja bagi karyawan. 
JUMANIS - BAJA VOL 4 NO 1 Prodi Kewirausahaan Februari 2022

ISSN : 2686-0554

ESSN : 2686-5939

DOI : 10.47080

Pemberian insentif kepada masing-masing karyawan yang berprestasi pada dasarnya untuk memancing dan mendorong mereka agar bekerja lebih giat dan lebih baik sehingga prestasi dapat lebih meningkat yang pada akhirnya tujuan perusahaan dapat tercapai. Selain untuk meningkatkan produktivitas kerja karyawan, sistem pemberian insentif dimaksudkan untuk mempertahankan karyawan yang berprestasi untuk tetap berada dalam perusahaan.

Keefektifan kinerja karyawan merupakan masalah yang yang harus dihadapi oleh perusahaan, dimana perusahaan harus lentur dan efisien supaya dapat berkembang dengan pesat. Bagi perusahaan kinerja yang efektif merupakan output yang harus dipertahankan. Karyawan akan bekerja secara optimal apabila pekerjaan mereka dapat memenuhi kebutuhan hidupnya. Artinya perusahaan harus benar-benar memperhatikan tingkat kebutuhan karyawannya. Kinerja yang tinggi dapat tercipta apabila karyawan merasa senang dan diperhatikan dalam bekerja. Dengan demikian karyawan mendapatkan apa yang diperolehnya dan dengan kinerjanya yang tinggi tersebut perusahaan dapat memperoleh keuntungan yang diinginkan.

\section{Perumusan Masalah}

Berdasarkan uraian diatas maka penulis mengidentifikasi masalah yang akan diteliti sebagai berikut :

1. Apakah Motivasi berpengaruh terhadap Kinerja karyawan pada PT. Bentara Sinergies Multi Finance

2. Apakah Insentif berpengaruh terhadap Kinerja karyawan pada PT. Bentara Sinergies Multi Finance

3. Apakah Motivasi dan Insentif berpengaruh terhadap Kinerja karyawan pada PT. Bentara Sinergies Multi Finance

\section{KAJIAN TEORI}

\section{Motivasi}

Menurut Mangkunegara (2009 : 93) mengemukakan Motivasi adalah sebagai berikut: “Motif merupakan suatu dorongan kebutuhan dalam diri pegawai yang perlu dipenuhi agar 
JUMANIS - BAJA VOL 4 NO 1 Prodi Kewirausahaan Februari 2022

ISSN : 2686-0554

ESSN : 2686-5939

DOI : 10.47080

pegawai tersebut dapat menyesuaikan diri terhadap lingkungannya, sedangkan motivasi adalah kondisi yang menggerakan pegawai agar mampu mencapai tujuan dari motifnya."

\section{Insentif}

Menurut Hasibuan (2008 : 118) mengemukakan Insentif adalah sebagai berikut : “ Insentif adalah tambahan balas jasa yang diberikan oleh karyawan tertentu yang prestasinya diatas prestasi standar, insentif merupakan alat yang dipergunakan untuk mendorong prinsip adil dalam pemberian kompensasi. "

\section{Kinerja}

Menurut Sutrisno (2009 : 165) mengemukakan kinerja adalah sebagai berikut: "Kinerja adalah sebagai hasil kerja yang telah dicapai seseorang dari tingkah laku kerjanya dalam melaksanakan aktivitas kerja."

\section{METODE PENELITIAN}

\section{Obyek Penelitian}

\section{Lokasi Penelitian}

Untuk mendapatkan informasi dan data yang diperlukan dalam penyusunan skripsi ini, maka penelitian ini akan dilakukan di PT. Bentara Sinergies Multi Finance yang berlokasi di Jl. Semanan Raya, Daan Mogot KM 16 No. 50 Kel. Semanan, Kec. Kalideres 11850, Jakarta, Indonesia

\section{Populasi}

Menurut Sugiyono (2007 : 72) menyatakan bahwa populasi adalah wilayah generalisasi yang terdiri atas: objek atau subjek yang mempunyai kualitas dan karasteristik tertentu yang ditetapkan peneliti untuk dipelajari dan kemudian ditarik kesimpulannya. Populasi dalam penelitian ini yaitu karyawan bagian produksi PT. Bentara Sinergies Multi Finance khususnya di departemen garment (bagian staff dan operator) yang berjumlah 133 orang. 
JUMANIS - BAJA VOL 4 NO 1 Prodi Kewirausahaan Februari 2022

ISSN : 2686-0554

ESSN : 2686-5939

DOI : 10.47080

\section{Sampel}

Menurut Sugiyono (2007 : 73) menyatakan bahwa sampel adalah bagian dari jumlah dan karasteristik yang dimiliki oleh populasi tersebut. Sampel dalam penelitian ini diambil dari jumlah populasi karyawan bagian garmen PT. Bentara Sinergies Multi Finance dengan jumlah 133 orang. Supaya dapat menentukan besaran sampel maka penulis memakai rumus slovin yaitu :

$$
n=\frac{N}{1+N e^{2}}=\frac{133}{1+133 \cdot\left(0.05^{2}\right)}=99,81238
$$

Dari hasil perhitungan di atas, jumlah sampel di bulatkan menjadi 100 orang.

Dimana :

n : jumlah sampel

$N \quad$ : jumlah populasi

e : batas toleransi kesalahan (error tolerance), diperkirakan batas toleransi kesalahan dalam pebelitian ini adalah 5\%)

\section{ANALISIS HASIL PEMBAHASAN}

Berdasarkan data yang telah disebar kepada karyawan produksi PT. Bentara Sinergies Multi Finance yang berlokasi di Jakarta dengan total 100 kuesioner yang diantarkan langsung kepada karyawan melalui HRD PT. Bentara Sinergies Multi Finance

Berikut ini diringkas pengiriman dan penerimaan kuesioner :

Tabel 3.9

Rincian Pengiriman Pengembalian Kuisioner

\begin{tabular}{|l|l|l|}
\hline Keterangan & Jumlah & Persentase \\
\hline Kuesioner yang dikirim & 100 & $100 \%$ \\
\hline Kuesioner yang tidak kembali & 0 & $0 \%$ \\
\hline Kuesioner yang kembali & 100 & $100 \%$ \\
\hline
\end{tabular}


JUMANIS - BAJA VOL 4 NO 1 Prodi Kewirausahaan Februari 2022

ISSN : 2686-0554

ESSN : 2686-5939

DOI : 10.47080

\begin{tabular}{|l|l|l|}
\hline Keterangan & Jumlah & Persentase \\
\hline Jumlah kuesioner yang digunakan & 100 & $100 \%$ \\
\hline
\end{tabular}

(Sumber: Data diolah penulis)

Sebelum melakukan pengujian statistik terlebih dahulu melihat profil responden karyawan PT. Bentara Sinergies Multi Finance. Profil ini didapat dari jawaban yang tercantum dalam kuesioner.

\section{Analisis Pengujian Data}

\section{a. Uji Validitas}

Uji validitas diukur dengan cara membandingkan nilai Pearson Correlation dengan rtabel. Jika $r_{\text {hitung }}>$ dari $r_{\text {tabel, }}$ maka item pertanyaan dinyatakan valid dan jika $r_{\text {hitung }}<$ dari $r$ tabel, maka item pertanyaan dinyatakan tidak valid. Nilai r-tabel di dapat dari degree of freedom $(\mathrm{df}=\mathrm{n}-2)$, dimana $\mathrm{n}$ adalah jumlah responden dengan $\alpha=0,05$. Dalam penelitian ini nilai $\mathrm{r}$-tabel yang didapat adalah 0,196 nilai tersebut didapat dari $(\mathrm{df}=100-2=98)$ dengan tingkat signifikan 0,05. Hasil uji validitas dapat dilihat dari tabel di bawah ini:

Tabel 4.8 Hasil Uji Validitas Variabel Motivasi $\left(\mathbf{X}_{1}\right)$

\begin{tabular}{|l|l|l|l|l|}
\hline No. & Indikator & Nilai Korelasi & $\begin{array}{l}\text { Probabilitas Korelasi } \\
\text { Sig. }(2 \text { tailed })\end{array}$ & Keterangan \\
\hline 1. & Motivasi 1 & 0,691 & 0,000 & \\
\hline 2. & Motivasi 2 & 0,658 & 0,000 & VALID \\
\hline 3. & Motivasi 3 & 0,674 & 0,000 & VALID \\
\hline 4. & Motivasi 4 & 0,664 & 0,000 & VALID \\
\hline 5. & Motivasi 5 & 0,723 & 0,000 & VALID \\
\hline
\end{tabular}

(Sumber: Hasil pengolahan data SPSS Versi 20) 
JUMANIS - BAJA VOL 4 NO 1 Prodi Kewirausahaan Februari 2022

ISSN : 2686-0554

ESSN : 2686-5939

DOI : 10.47080

Tabel 4.9 Hasil Uji Validitas Variabel Insentif $\left(\mathbf{X}_{2}\right)$

\begin{tabular}{|l|l|l|l|l|}
\hline No. & Indikator & Nilai Korelasi & $\begin{array}{l}\text { Probabilitas Korelasi } \\
\text { Sig. (2 tailed })\end{array}$ & Keterangan \\
\hline 1. & Insentif 1 & 0,708 & 0,000 & VALID \\
\hline 2. & Insentif 2 & 0,702 & 0,000 & VALID \\
\hline 3. & Insentif 3 & 0,620 & 0,000 & VALID \\
\hline 4. & Insentif 4 & 0,709 & 0,000 & VALID \\
\hline
\end{tabular}

(Sumber: Hasil pengolahan data SPSS Versi 2.0)

Tabel 4.10 Hasil Uji Validitas Variabel Kinerja (Y)

\begin{tabular}{|l|l|l|l|l|}
\hline No. & Indikator & Nilai Korelasi & $\begin{array}{l}\text { Probabilitas } \\
\text { Korelasi Sig. }(2 \\
\text { tailed) } \\
\text { Corellation) }\end{array}$ & Keterangan \\
\hline 1. & Kinerja 1 & 0,531 & 0,000 & VALID \\
\hline 2. & Kinerja 2 & 0,351 & 0,000 & VALID \\
\hline 3. & Kinerja 3 & 0,443 & 0,000 & VALID \\
\hline 4. & Kinerja 4 & 0,434 & 0,000 & VALID \\
\hline 5. & Kinerja 5 & 0,617 & 0,000 & VALID \\
\hline 6. & Kinerja 6 & 0,812 & 0,000 & VALID \\
\hline 7. & Kinerja 7 & 0,423 & 0,000 & VALID \\
\hline 8. & Kinerja 8 & 0,458 & 0,000 & \\
\hline 9. & Kinerja 9 & 0,606 & 0,000 & \\
\hline
\end{tabular}


JUMANIS - BAJA VOL 4 NO 1 Prodi Kewirausahaan Februari 2022

ISSN : 2686-0554

ESSN : 2686-5939

DOI : 10.47080

\begin{tabular}{|l|l|l|l|l|}
\hline No. & Indikator & $\begin{array}{l}\text { Nilai Korelasi } \\
\text { (Pearson } \\
\text { Corellation) }\end{array}$ & $\begin{array}{l}\text { Probabilitas } \\
\text { Korelasi Sig. } \quad(2 \\
\text { tailed) }\end{array}$ & Keterangan \\
\hline 10. & Kinerja 10 & 0,589 & 0,000 & VALID \\
\hline 11. & Kinerja 11 & 0,343 & 0,000 & VALID \\
\hline 12 & Kinerja 12 & 0,426 & 0,000 & VALID \\
\hline 13. & Kinerja 13 & 0,415 & 0,000 & VALID \\
\hline 14. & Kinerja 14 & 0,754 & 0,000 & \\
\hline
\end{tabular}

(Sumber: Hasil pengolahan data SPSS Versi 2.0)

Berdasarkan hasil olah data pada tabel diatas terlihat bahwa semua item pertanyaan memiliki nilai $\mathrm{r}_{\text {hitung }}>$ dari $\mathrm{r}_{\text {tabel }}$ yaitu 0,196, maka dapat disimpulkan bahwa item pertanyaan yang digunakan untuk mengukur Motivasi, Insentif dan Kinerja dinyatakan valid.

\section{b. Uji Reliabilitas}

Uji reliabilitas digunakan untuk menguji konsistensi jawaban responden atas seluruh bukti pertanyaan. Suatu kuesioner dikatakan reliabel atau handal jika jawaban seseorang terhadap pernyataan adalah konsisten atau stabil dari waktu ke waktu (Ghozali, 2011 : 47). Suatu variabel dapat dikatakan reliabel apabila nilai cronbach's alpha dari variabel tersebut $>0,60$. Hasil pengujian reliabilitas ditampilkan dalam tabel berikut ini :

Tabel 4.11

Hasil Uji Reliabilitas

\begin{tabular}{|l|l|l|l|}
\hline Variabel & $\begin{array}{l}\text { Jumlah Butir } \\
\text { Pertanyaan }\end{array}$ & Cronbach alpha & Keterangan \\
\hline Motivasi $\left(\mathrm{X}_{1}\right)$ & 5 & 0,703 & RELIABEL \\
\hline Insentif $\left(\mathrm{X}_{2}\right)$ & 4 & 0,623 & RELIABEL \\
\hline Kinerja (Y) & 14 & 0,793 & RELIABEL \\
\hline
\end{tabular}

(Sumber: Hasil pengolahan data SPSS Versi 20) 
Berdasarkan tabel 4.11 menunjukan bahwa pada variabel Motivasi nilai cronbach alpha 0,703, nilai cronbach alpha variabel Insentif 0,623, dan cronbach alpha variabel Kinerja 0,793. Sehingga dapat disimpulkan bahwa instrument untuk setiap variabel penelitain adalah reliabel, karena nilai cronbach's alpha dari semua variabel yang di uji memiliki nilai $>0,60$.

\section{Uji Asumsi Klasik}

\section{a. Uji Normalitas}

Sebelum melakukan pengujian hipotesis, dilakukan pengujian asumsi klasik. Pengujian ini dilakukan untuk mendeteksi terpenuhinya asumsi-asumsi dalam model regresi berganda dan untuk menginterprestasikan data agar lebih relevan dalam menganalisis. Dalam penelitian ini uji autokorelasi tidak digunakan karena dalam data primer dalam bentuk kuesioner dan tidak berhubungan dengan data time series atau rentang waktu.

Uji normalitas yang digunakan dalam penelitian ini adalah dengan menggunakan uji one sample kolmogorov smirnov yang dapat dilihat pada signifikasi, apabila nilai signifikan > 0,05 maka data dikatakan terdistribusi dengan normal dan normal probability plot yang dapat dilihat pada penyebaran data yang berupa titik-titik pada sumbu diagonal dari grafik, jika data menyebar disekitar garis diagonal dan mengikuti arah garis diagonal maka model regresi tersebut memenuhi asumsi normalitas dan sebaliknya, jika data menyebar jauh dari garis diagonal dan tidak mengikuti arah garis diagonal maka model regresi tersebut tidak berdistribusi secara normal.

Tabel 4.12

Hasil Uji Normalitas

One-Sample Kolmogorov-Smirnov Test

\begin{tabular}{|ll|l|}
\hline & & $\begin{array}{l}\text { Unstandardiz } \\
\text { ed Predicted } \\
\text { Value }\end{array}$ \\
\hline $\mathrm{N}$ & Mean & 100 \\
& OE-7 \\
Normal Parameters $^{\mathrm{a}, \mathrm{b}}$ & Std. & 3.71734505 \\
& Deviation &
\end{tabular}


JUMANIS - BAJA VOL 4 NO 1 Prodi Kewirausahaan Februari 2022

ISSN : 2686-0554

ESSN : 2686-5939

DOI : $\mathbf{1 0 . 4 7 0 8 0}$

\begin{tabular}{|ll|l|} 
& Absolute & .091 \\
Most Extreme & Positive & .057 \\
Differences & Negative & -.091 \\
Kolmogorov-Smirnov Z & .911 \\
Asymp. Sig. (2-tailed) & & .378 \\
\hline
\end{tabular}

a. Test distribution is Normal.

b. Calculated from data.

(Sumber: Hasil pengolahan data SPSS Versi 20)

Dari tabel diatas diketahui nilai Kolmogorov Smirnov 0,911 dan signifikan pada 0, 378. Nilai sig lebih besar dari 0,05 sehingga dapat ditarik kesimpulan bahwa data yang digunakan dalam penelitian ini terdistribusi secara normal.

Gambar 4.1

\section{Hasil Uji Normalitas}

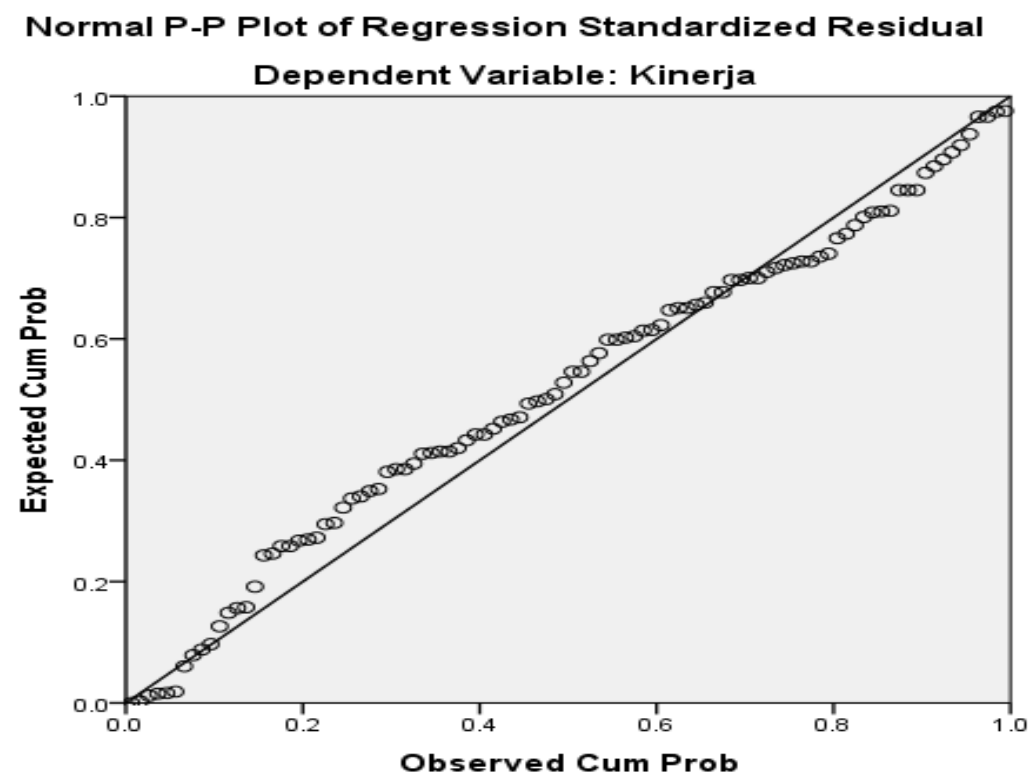

(Sumber: Hasil pengolahan data SPSS Versi 20)

Dari gambar grafik diatas dapat dilihat bahwa titik-titik menyebar disekitar garis diagonal dan mengikuti arah garis diagonal. Sehingga dapat disimpulkan bahwa data dalam penelitian ini terdistribusi secara normal. 
JUMANIS - BAJA VOL 4 NO 1 Prodi Kewirausahaan Februari 2022

ISSN : 2686-0554

ESSN : 2686-5939

DOI : 10.47080

\section{b. Uji Heteroskedastisitas}

Uji Heteroskedasitas dilakukan untuk menguji apakah dalam suatu model regresi terjadi ketidaksamaan varian dari residual dari satu pengamatan ke pengamatan lain. Jika varian dari residual dari satu pengamatan ke pengamatan lain tetap, maka disebut Homoskedastisitas. Jika varian berbeda disebut Heteroskedasitas. Model regresi yang baik adalah tidak terjadi Heteroskedastisitas. Adapun grafik hasil uji heteroskedastisitas adalah sebagai berikut :

Gambar 4.2

\section{Hasil Uji Heteroskedastisitas}

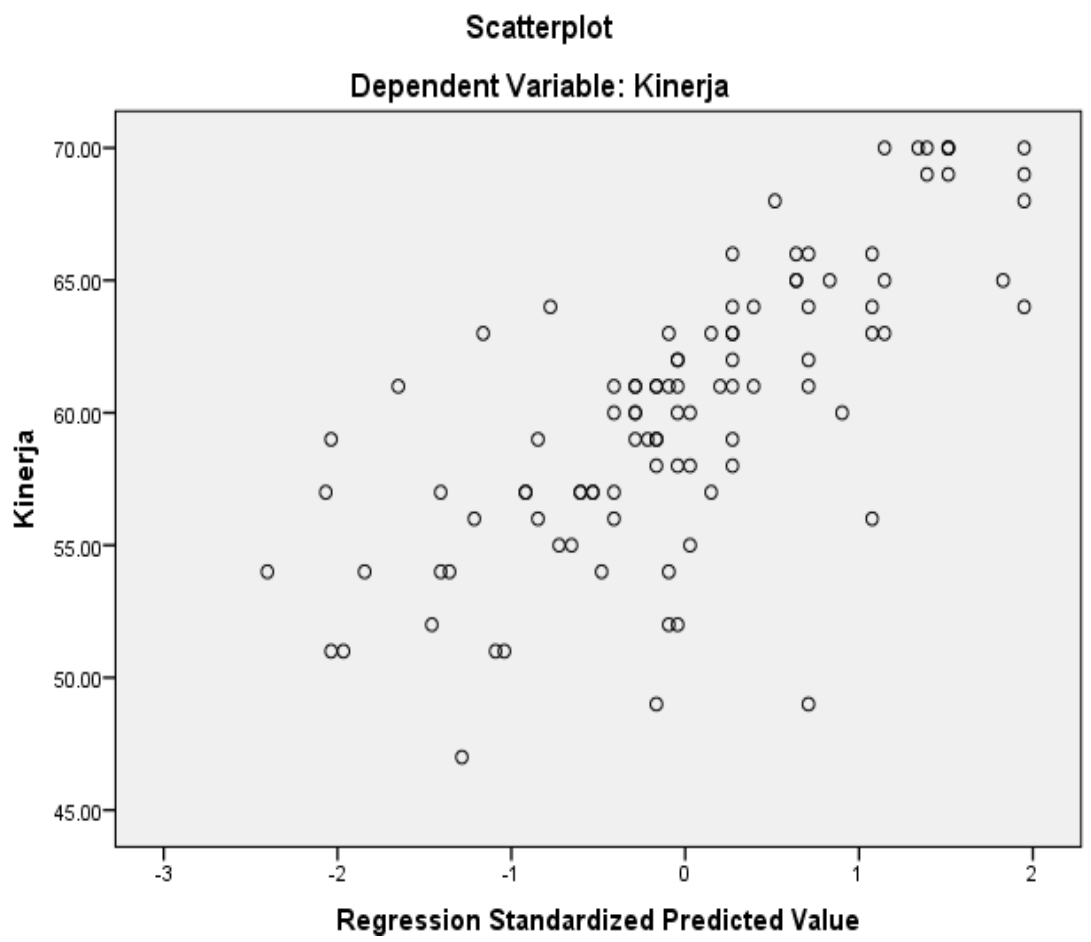

(Sumber: Hasil pengolahan data SPSS Versi 20)

Pada Gambar 4.2 diatas terlihat titik-titik yang menyebar secara acak, tidak membentuk suatu pola tertentu yang jelas, serta tersebar baik diatas maupun di bawah angka 0 (nol) pada sumbu Y. Hal ini berarti tidak terjadi heteroskedastisitas pada model regresi, sehingga model regresi layak digunakan untuk memprediksi Y.

\section{c. Uji Multikolinieritas}

Uji multikolonieritas ini digunakan untuk mengetahui apakah dalam model regresi ditemukan adanya kolerasi antar variabel independen, yaitu: Motivasi dan Insentif. Uji multikolinieritas dilakukan dengan cara melihat (1) nilai tolerance dan (2) variance inflation factor (VIF). Dibawah ini merupakan hasil pengiujian multikolinieritas. 
Tabel 4.13

\section{Hasil Uji Multikolonieritas}

\section{Coefficients $^{\mathrm{a}}$}

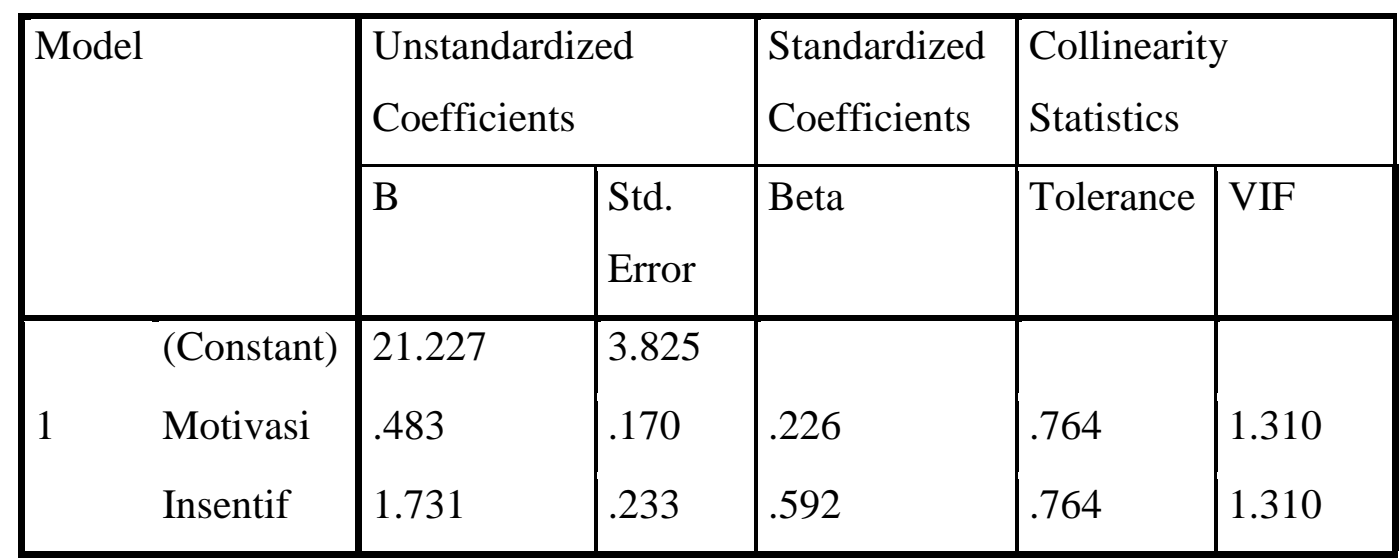

a. Dependent Variable: Kinerja

\section{(Sumber: Hasil pengolahan data SPSS Versi 20)}

Tabel diatas menunjukkan bahwa nilai tolerance dari masing-masing variabel independen, yaitu Motivasi $\left(\mathrm{X}_{1}\right)$ sebesar 0.764, Insentif $\left(\mathrm{X}_{2}\right)$ sebesar 0.764. Dari output diatas juga diketahui nilai variance inflation factor (VIF) masing-masing variabel independen, yaitu Motivasi $\left(\mathrm{X}_{1}\right)$ sebesar 1.310, Insentif $\left(\mathrm{X}_{2}\right)$ sebesar 1.310. Kedua variabel independen tersebut memiliki nilai tolerance diatas 0,1 dan nilai VIF dibawah 10, sehingga dapat disimpulkan bahwa tidak terjadi multikolinearitas antar variabel independen.

\section{Kesimpulan}

Setelah penulis melakukan penelitian dan pembahasan pada bab sebelumnya mengenai "Pengaruh Motivasi dan Insentif terhadap Kinerja Karyawan (Study Kasus pada PT. Bentara Sinergies Multi Finance Factory)”, maka penulis mengambil kesimpulan sebagai berikut :

1. Berdasarkan hasil perhitungan bahwa variabel bebas Motivasi berpengaruh signifikan terhadap variabel terikat Kinerja Karyawan dikarenakan memiliki nilai signifikan lebih kecil.

2. Berdasarkan hasil perhitungan bahwa variabel bebas Insentif berpengaruh signifikan terhadap variabel terikat kinerja Karyawan dikarenakan memiliki nilai signifikan lebih kecil. 
JUMANIS - BAJA VOL 4 NO 1 Prodi Kewirausahaan Februari 2022

ISSN : 2686-0554

ESSN : 2686-5939

DOI : 10.47080

3. Variabel bebas Motivasi dan Insentif berpengaruh signifikan terhadap variable terikat Kinerja Karyawan.

\section{Saran}

Setelah melihat kesimpulan diatas berikut saran yang mungkin berguna dan data dipakai sebagai pertimbangan bagi pihak PT. Bentara Sinergies Multi Finance Factory :

1. Karena terdapat pengaruh yang signifikan antara Motivasi terhadap kinerja karyawan, untuk membantu mempengaruhi karyawan dalam hal meningkatkan kinerja, maka pemberian Motivasi harus lebih ditingkatkan, seperti pengarahan atasan kepada bawahan harus di tingkatkan, mengadakan rutinitas karyawan seperti bermain futsal bersama, memberikan contoh yang baik kepada karyawan atau mengadakan rapat santai sambil makan-makan kepada para karyawan.

2. Karena terdapat pengaruh yang signifikan antara Insentif terhadap kinerja karyawan, untuk membantu mempengaruhi karyawan dalam hal meningkatkan kinerja, maka pemberian Insentif harus lebih ditingkatkan, seperti menambah jam lembur dan menaikkan upah lembur para karyawan. Dengan begitu karyawan akan lebih loyal dalam bekerja dan meningkatkan profit perusahaan.

\section{DAFTAR PUSTAKA}

Dessler, Gary. 2006. Manajemen Sumber Daya Manusia, Edisi Kesepuluh Jilid 1. Terjemahan oleh Paramita Rahayu dari Human Resource Management, Tenth Edition (2003). Jakarta: PT Indeks.

Ghozali, Imam. 2005. Analisis Multivariat dengan Program SPSS. Semarang: Badan Penerbit Universitas Diponegoro.

2011. Aplikasi Analisis Multivariat dengan Program IBM SPSS20. Semarang: Badan Penerbit Universitas Diponegoro.

Hasibuan, Malayu S.P. 2008. Manajemen Sumber Daya Manusia, Edisi Revisi. Jakarta: PT Bumi Aksara. 
JUMANIS - BAJA VOL 4 NO 1 Prodi Kewirausahaan Februari 2022

ISSN : 2686-0554

ESSN : 2686-5939

DOI : 10.47080

Mangkunegara, Anwar Prabu. 2009. Manajemen Sumber Daya Manusia Perusahaan. Bandung: PT Remaja Rosdakarya.

Rahmatina, Desi. 2009. Uji Multikolonieritas. (online), (http://desirahmatina.blogspot.com/2009/03/uji-multikolonieritas.html?m=1, diakses 27 Desember 2013).

Robbins, Stephen. 2006. Perilaku Organisasi (10 ${ }^{\text {th }}$ ed). Hall: New Jerssey Inc Indeks.

Samsudin, Sadili. 2006. Manajemen Sumber Daya Manusia, Cetakan ke-1. Bandung: Pustaka Setia.

Sevilla, Consuelo G. et. al. 2007. Research Methods. Rex Printing Company. Quezon City. (online), (http://analisis-statistika.blogspot.com/2012/09/menentukan-jumlah-sampeldengan-rumus.html?m=1, diakses 6 Juni 2013).

Sirait, Justine T. 2006. Memahami Aspek-Aspek Pengelolaan Sumber Daya Manusia Dalam Organisasi. Jakarta: PT Grasindo.

Sugiyono. 2007. Metode Penelitian Bisnis. Bandung: Alfabeta, CV. . 2012. Metode Penelitian Kuantitatif, Kualitatif, dan R\&D. Bandung: Alfabeta, CV.

Sutrisno, Edy. 2009. Manajemen Sumber Daya Manusia, Edisi Pertama, Cetakan ke-1. Jakarta: Prenada Media.

Wayne, R. Mondy. 2008. Manajemen Sumber Daya Manusia, Jilid 1 Edisi 10. Terjemahan oleh Bayu Airlangga dari Human Resource Management, Tenth Edition (2008). Jakarta: Penerbit Erlangga.

Widiantoro, Prima. 2012. Pengaruh Motivasi Terhadap Kinerja Karyawan pada PT. Wom Finance, tbk

Imbarwati, Triyani. 2012. Pengaruh Insentif Terhadap Kinerja Karyawan pada PT. Wahana Ottomitra Multi Artha Finance

www.google.co.id www.muliaknittingfactory.co.id 